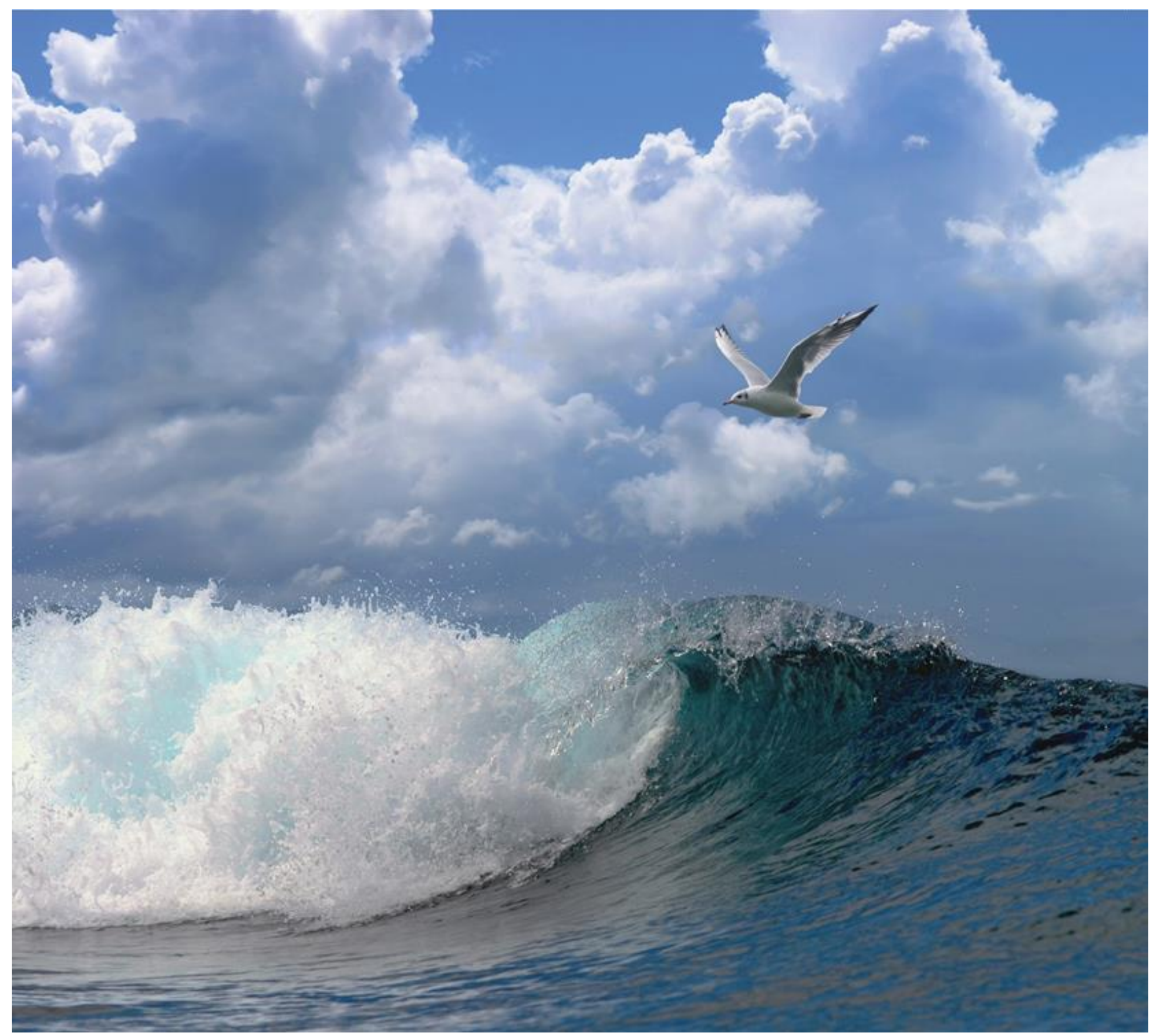

\title{
Taxonomische status van houting in Nederlandse wateren
}




\title{
Taxonomische status van houting in Nederlandse wateren
}

\author{
Auteur(s): $\quad$ H.V. Winter
}

Publicatiedatum: December 2017

Dit onderzoek is uitgevoerd door Wageningen Marine Research in opdracht van en gefinancierd door het Ministerie van Economische Zaken, in het kader van de Wettelijke Onderzoekstaken Visserij (WOT05 Visserij)

Wageningen Marine Research IJmuiden, december 2017

Wageningen Marine Research rapport C115/17 
H.V. Winter, 2017. Taxonomische status van houting in Nederlandse wateren. Wageningen Marine Research Wageningen UR (University \& Research centre), Wageningen Marine Research rapport C115/17. 17 blz.

Keywords: houting, taxonomie, Nederland.

Opdrachtgever: Ministerie LNV

T.a.v. ir. H.R. Offringa

Bezuidenhoutseweg 73

2594 AC Den Haag

BAS code WOT-05-001-016

Dit rapport is gratis te downloaden van https://doi.org/10.18174/430139

Wageningen Marine Research verstrekt geen gedrukte exemplaren van rapporten.

Wageningen Marine Research Wageningen UR is ISO 9001:2008 gecertificeerd.

(C) 2017 Wageningen Marine Research

Wageningen Marine Research, onderdeel van Stichting DLO.

KvK nr. 09098104,

IMARES BTW nr. NL 8113.83.696.B16

Code BIC/SWIFT address: RABONL2U

IBAN code: NL 73 RABO 0373599285
De Directie van Wageningen Marine Research is niet aansprakelijk voor gevolgschade, noch voor schade welke voortvloeit uit toepassingen van de resultaten van werkzaamheden of andere gegevens verkregen van IMARES; opdrachtgever vrijwaart IMARES van aanspraken van derden in verband met deze toepassing.

Dit rapport is vervaardigd op verzoek van de opdrachtgever hierboven aangegeven en is zijn eigendom. Niets uit dit rapport mag weergegeven en/of gepubliceerd worden, gefotokopieerd of op enige andere manier gebruikt worden zonder schriftelijke toestemming van de opdrachtgever. 


\section{Inhoud}

$\begin{array}{lr}\text { Samenvatting } & 4\end{array}$

$\begin{array}{llr}1 & \text { Inleiding } & 5\end{array}$

2 Kennisvraag $\quad 6$

$3 \quad$ Historische ontwikkeling en verspreiding van houting 7

$\begin{array}{lll}3.1 & \text { Achteruitgang } & 7\end{array}$

3.2 Bescherming en herintroductie $\quad 8$

$\begin{array}{ll}3.3 & \text { Houting in het mariene milieu }\end{array}$

4 Taxonomie van houtingachtigen $\quad 10$

4.1 De complexiteit van de taxonomie $\quad 10$

4.2 Was de uitgestorven 'Rijn-houting' een aparte soort? $\quad 10$

4.2.1 2005: de uitgestorven 'Rijn-houting' was een aparte soort 10

4.2.2 Wetenschappelijke kritiek en recentere inzichten 11

$5 \quad$ Conclusies en aanbevelingen 12

$\begin{array}{llr}6 & \text { Kwaliteitsborging } & 13\end{array}$

$\begin{array}{lr}\text { Literatuur } & 14\end{array}$

$\begin{array}{lr}\text { Verantwoording } & 16\end{array}$ 


\section{Samenvatting}

Houting (Coregonus oxyrhinchus) is één van de riviertrekvissen, naast Europese steur, Atlantische zalm en elft, die in de loop van de 20ste eeuw is uitgestorven in de Nederlandse stroomgebieden en na 1940 niet meer werd aangetroffen. Nadat er in 1992 een grootschalig herintroductieprogramma van houting werd gestart in de Duitse Rijn op basis van de laatste houting populatie in de Deense Waddenzee zijn houtingen weer in toenemende mate aangetroffen in de Nederlandse grote rivieren en het IJsselmeergebied.

Momenteel bestaat onduidelijkheid over de taxonomische status van de houtingen die nu in Nederlandse wateren worden aangetroffen aangezien na het verschijnen van de claim van Freyhof en Schöter (2005) veel wetenschappelijke kritiek gekomen op hun onderbouwing dat de oorspronkelijke houting in de Nederlandse wateren een aparte soort betrof.

De claim van Freyhof \& Schöter (2005) dat de uitgestorven populatie in de Rijn-delta een aparte soort is en dat $C$. oryrinchus dus een wereldwijd uitgestorven soort betrof, is daarna, afgezien door de IUCN, niet overgenomen door de wetenschappelijke wereld. Integendeel, er is veel kritiek op de veel te smalle onderbouwing hiervoor.

Wat wel is aangetoond is dat de houting uit de Deense Waddenzee zowel genetisch, als ook morfologisch (o.a. in hoge mate van zouttolerantie, een zeer zeldzaam voorkomende eigenschap onder de houtingachtigen), verschilt van de Baltische houting (C. maraena) rondom de Oostzee.

De enige manier om duidelijkheid te krijgen over de status van de houtingpopulatie die in de jaren '30 van de $20^{\mathrm{e}}$ eeuw verdwenen is uit de Rijn-delta is aan de hand van genetisch onderzoek van historisch materiaal. Er zijn in collecties nog wel schubben en ander niet in formaline geconserveerd materiaal van houtingen beschikbaar die onderzocht zouden kunnen worden en er zijn methoden ontwikkeld om hier goede genetische profielen uit op te stellen. Met een dergelijk genetisch onderzoek zou kunnen worden bepaald of de Rijn-delta houting een aparte soortstatus verdiende. 


\section{$1 \quad$ Inleiding}

Houting (Coregonus oxyrhinchus) is één van de riviertrekvissen, naast Europese steur (Acipenser sturio), Atlantische zalm (Salmo salar) en elft (Alosa alosa), die in de loop van de 20ste eeuw is uitgestorven in de Nederlandse stroomgebieden en na 1940 niet meer werd aangetroffen. Nadat in 1992 een grootschalig herintroductieprogramma van houting werd gestart in de Duitse Rijn op basis van de laatste houting populatie in de Deense Waddenzee, zijn houtingen weer in toenemende mate aangetroffen in de Nederlandse grote rivieren en het IJsselmeergebied.

Naast houtingen, te herkennen aan de vlezige puntige neus, onderstandige bek en 80-90 schubben op de zijlijn, worden in Nederland ook af en toe coregoniden zonder puntige neus aangetroffen met een licht onderstandige bek en 95-98 schubben op de zijlijn, die aangeduid worden met 'grote marene'. De herkomst van deze marenen is vaak niet goed bekend, maar maken deel uit van het Coregonus lavaretus-complex. De taxonomie van deze grote marene wordt in deze rapportage buiten beschouwing gelaten. 


\section{Kennisvraag}

$\mathrm{Er}$ is momenteel onduidelijkheid over de taxonomische status van de houtingen die nu in Nederlandse wateren worden aangetroffen. De International Union for Conservation of Nature (IUCN ) beschouwt de houting Coregonus oxyrhinchus die vroeger voorkwam in het Rijn-, Maas- en Scheldegebied als een aparte soort die zich onderscheidt van de houting zoals die in de Deense Waddenzee, waar deze maar net voor uitsterven is behoed. De IUCN baseert zich daarbij op een claim van Freyhof en Schöter (2005). Daarmee beschouwt de IUCN de houting als wereldwijd uitgestorven soort. Dit zou betekenen dat de Deense houting, die voor de herintroductieprogramma's zijn gebruikt, een niet inheemse soort voor Nederland betrof, met belangrijke consequenties voor het natuurbeleid en -beheer (o.a. EU Vogel- en Habitatrichtlijn en Natura 2000) en visserijbeleid en -beheer.

Na het verschijnen van de claim van Freyhof en Schöter (2005) is echter veel wetenschappelijke kritiek gekomen op hun onderbouwing dat de oorspronkelijke houting in de Nederlandse wateren een aparte soort betrof. Dit debat wordt hieronder verder besproken met als centrale vraag:

Behoren de houtingen die nu in Nederland worden aangetroffen tot de ernstig bedreigde soort Coregonus oxyrinchus, of is de houting die vanuit de Deense Waddenzee in de Rijn is uitgezet binnen een herintroductie programma een andere soort? 


\section{Historische ontwikkeling en verspreiding van houting}

\section{$3.1 \quad$ Achteruitgang}

Houtingen kwamen oorspronkelijk uitsluitend voor in de stroomgebieden die uitmonden in de Waddenzee (kleine Deense rivieren, Elbe, Weser, Eems), de Rijn, Maas en Schelde stroomgebieden (figuur 1) en wellicht ook in zuidoostelijk Engeland (Freyhof \& Schöter, 2005), al is dat laatste niet zeker. Daarmee is het een endemische soort voor de zuidelijke Noordzee.

In de loop van de 20ste eeuw zijn houtingen vrijwel overal verdwenen. In Nederland gebeurde dit in de jaren '30 van de vorige eeuw (de Groot 1988, 1990a, 1990b, 2002, zie ook figuur 2). Alleen in het Deense riviertje de Vidaa heeft zich een kleine populatie van enkele duizenden volwassen houtingen weten te handhaven (Jensen et al. 2003, Jepsen et al. 2012). In enkele kleine rivieren ten noorden van de Vidaa wordt, op zeer geringe schaal, af en toe natuurlijke paai waargenomen.

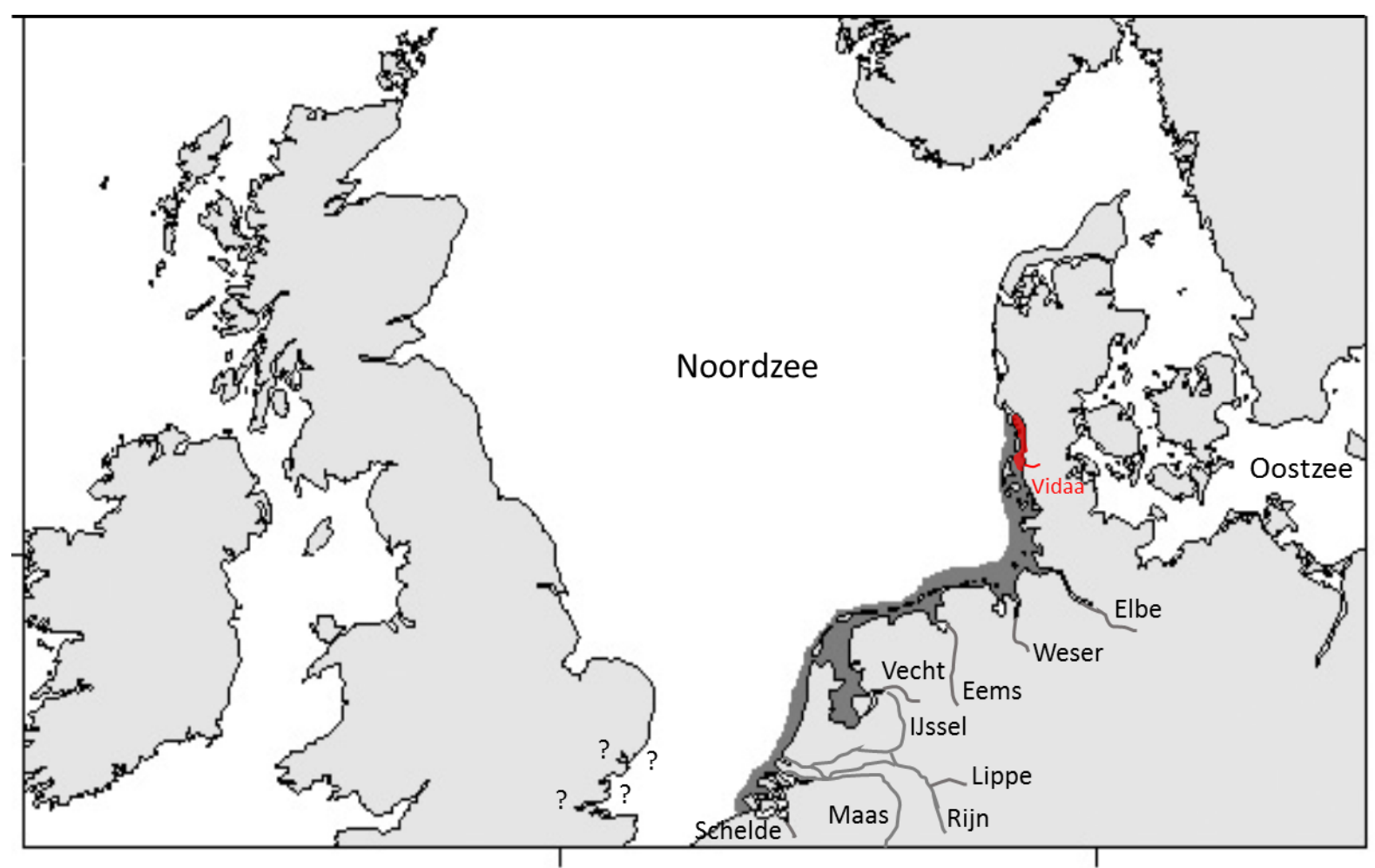

Figuur 1. Het historische verspreidingsgebied van houtingen in zee en belangrijke rivieren (donkergrijs) en de verspreiding rond 1985 (rood) rondom de Vidaa in het Deense Waddengebied (Naar Jensen et al. 2003, Hansen et al. 2005, en Jepsen et al. 2012). Nadien is de verspreiding van houting door uitzettingen in Sleeswijk-Holstein en het Rijn-stroomgebied weer groter geworden. Het historisch voorkomen van houting voor de Zuidoostelijke Engelse kust is onzeker. 


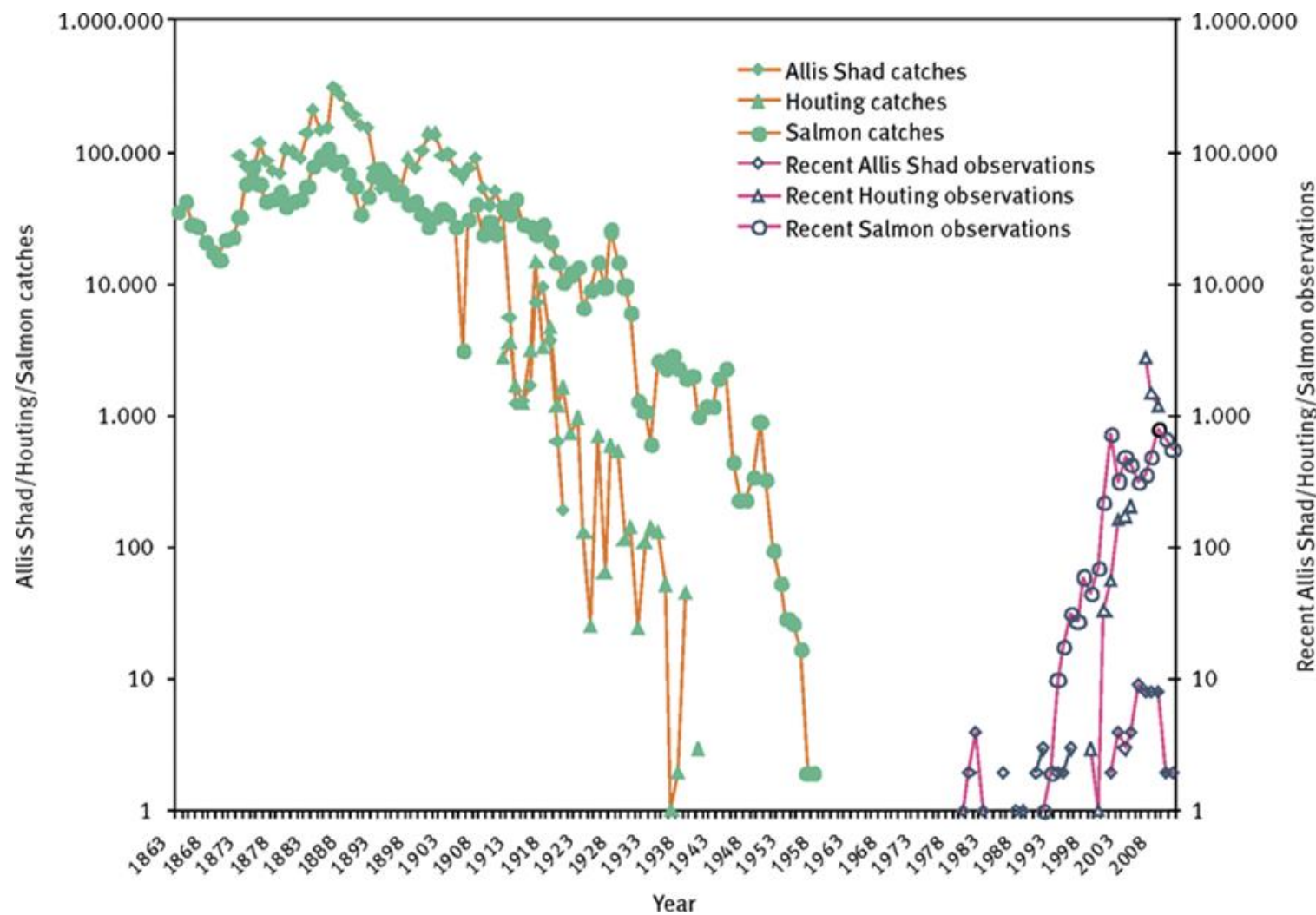

Figuur 2. Vangsten van de drie soorten riviertrekvissen in de Rijn die zijn uitgestorven in de 1e helft van de $20^{\text {ste }}$ eeuw en vanaf de jaren ' 80 van de $20^{\circ}$ eeuw zijn geherintroduceerd: houting, elft ('allis shad', Alosa alosa) en zalm ('salmon', Salmo salar), naar Ingendahl \& Beeck, 2011.

\subsection{Bescherming en herintroductie}

De houting heeft de hoogste beschermingsgraad (Annex II en IV) gekregen binnen de Vogel- en Habitatrichtlijn. De bescherming van de ernstig bedreigde houting is in 2005 met een groot EU LIFE project in Denemarken verder gestimuleerd (Jepsen et al. 2012). Deze Deense houtingen zijn sinds de jaren '90 van de vorige eeuw ook opgekweekt in gevangenschap en gebruikt voor herintroductieprogramma's in rivieren in Noord-Duitsland en de Duitse Rijn en Lippe net over de Nederlandse grens. Door deze uitzettingen komen houtingen nu in meerdere stroomgebieden die uitmonden in de Waddenzee weer voor, bijvoorbeeld in Sleeswijk-Holstein (o.a. de Treene) en het Rijnstroomgebied.

De uitzettingen in de Duitse Rijn en Lippe zijn in 1992 als pilot gestart. Tussen 1996 en 2006 zijn daar vervolgens jaarlijks tot 400.000 jonge houtingen uitgezet (Borcherding et al. 2006). Het uitzetten is na 2006 stopgezet, nadat was vastgesteld dat er naast de uitzettingen ook veel natuurlijke reproductie plaatsvond. Dat kon geconcludeerd worden op basis van een merkexperiment met chemische markeringen (Borcherding et al. 2010). In 2006 zijn in de Duitse Rijn en Lippe alle 400.000 uitgezette jonge houtingen gemerkt met Alizarin. Dit kleurmerk kan worden teruggevonden in de otolieten (gehoorsteentjes). Slechts 2 van de 55 eerstejaars houtingen die in 2006 in het IJsselmeer waren gevangen hadden het Alizarin merk op de otolieten, waaruit geconcludeerd kon worden dat de overgrote meerderheid van de jonge houting uit natuurlijke paai afkomstig moet zijn (Borcherding et al. 2010). Houting heeft zich ook na het stoppen van de uitzettingen gehandhaafd en vormt in het benedenstroomgebied van de Rijn en met name ook op het IJsselmeer en IJssel inmiddels een zichzelf in stand houdende populatie (Borcherding et al. 2008, 2010, 2014). 


\subsection{Houting in het mariene milieu}

De verspreiding of dispersie van houtingen tussen verschillende rivierpopulaties via mariene habitats lijkt zeer gering, gezien het beperkte voorkomen in het verleden in het mariene milieu en de afwezigheid van 'strayers' (dwaalgasten) vanuit Denemarken in gebieden nadat houtingen daar als paaipopulaties waren uitgestorven. Ook de zeldzaamheid en kleine omvang van de laatste natuurlijke populatie zal hier sterk aan hebben bijgedragen. Uit historische literatuur blijkt dat de houting in Nederland vooral in de benedenstroomse delen van de Schelde, Maas, Rijn, IJssel en Zwarte water/Vecht voorkwam. Houting werd veel in de brakke zones van de Zuiderzee en Zuid-Hollandse en Zeeuwse delta gevangen (Redeke 1934, 1941). De houting werd soms ook langs de Noordzeekust, in de Dollard (Schegel 1862, van Bemmelen 1966) en in de Waddenzee bij Den Helder (Redeke 1941) waargenomen. Meer recentelijk wordt houting buitengaats, met name aan de zeezijde van het Haringvliet en de Waddenzeezijde bij Den Oever en Kornwerderzand, waargenomen en er is één houting gevangen in een kom (oud vangtuig) bij Texel (Hans Witte, pers. obs.). Tenminste een deel van de huidige houtingen voltooit zijn levenscyclus volledig op zoet water (Borcherding et al. 2008). 


\section{$4 \quad$ Taxonomie van houtingachtigen}

\subsection{De complexiteit van de taxonomie}

Houtingachtigen (Coregoniden of Marenen) zijn wijdverspreid in het noordelijke deel van de wereld (Noord-Amerika en Eurazië) en vertonen grote variatie in morfologie en verschijningsvormen (morphen), waarbij de taxonomie en fylogenie (de beschrijving van hoe de ene groep organismen is ontstaan uit andere groepen) zeer problematisch is gebleken (Hansen et al. 1999, Praebel et al. 2013). De houting maakt onderdeel uit van het Coregonus lavaretus- soortencomplex in Europa. Coregoniden populaties bevinden zich sinds de laatste ijstijden in een snel proces tot soortvorming ('adaptive radiation'), enerzijds door isolatie en herkolonisatie in tal van koude meren en rivieren en anderzijds door een veranderende omgeving. Of en wanneer een populatie coregoniden tot een aparte soort moet worden beschouwd is vaak controversieel en tot op zekere hoogte subjectief (Hansen et al. 2008). Waar de meest conservatieve taxonomische insteek slechts twee Coregonus soorten in Europa onderscheidt (C. lavaretus en C. albula), gaan Kottelat en Freyhof (2007) het meest ver en onderscheiden zelfs meer dan 50 Coregonus soorten in Europa. Er is wel brede consensus dat het Coregonus soorten-complex in Europa bestaat uit een wolk populaties die zich snel tot aparte soorten aan het ontwikkelen zijn (Jacobsen et al. 2012).

\subsection{Was de uitgestorven 'Rijn-houting' een aparte soort?}

\subsubsection{5: de uitgestorven 'Rijn-houting' was een aparte soort}

Freyhof en Schöter (2005) hebben morfologisch onderzoek uitgevoerd naar zestien museumexemplaren van houting uit de benedenstroomse delen van de Rijn, Maas en Schelde. De museumexemplaren die Freyhof en Schöter (2005) onderzochten waren gefixeerd in formaline en daarmee ongeschikt voor genetisch onderzoek. Deze hebben ze vergeleken met de huidige Deense populatie houting en andere marenepopulaties rond Denemarken en de westelijke Oostzee. Op basis van verschillen in het aantal kieuwboogaanhangsels tussen de houting uit het Rijn-MaasScheldestroomgebied en de Vidaa claimen zij dat de uitgestorven houtingpopulatie in Nederland en België tot een andere soort behoorde dan de houting in Denemarken. Ze suggereren dat de Deense en Oostzee houtingen sinds de laatste ijstijd, vanuit een refugium vanuit de Elbe, de Duitse Waddenzee tot aan de Eems, en verder naar de Deense Wadden, Denemarken en Oostzee regio hebben gekoloniseerd. Daarbij stellen ze dat de Rijn-delta houting na de laatste ijstijd vanuit een refugium in de Rijn aan kolonisatie van de Nederlandse delta is begonnen.

De IUCN heeft de visie van Freyhof en Schöter overgenomen, c.q. Freyhof en Kottelat zijn gevraagd om de soortstatus en soortbeschrijvingen van coregoniden voor de IUCN te schrijven en beschouwt derhalve de houting ('North Sea Houting') Coregonus oryrinchus als een wereldwijd uitgestorven vissoort (Freyhof \& Kotelat 2008). De IUCN beschouwt de houting uit de Deense Waddenzee als behorende tot de soort Coregonus maraena, die voornamelijk in de Oostzee en instromende rivieren voorkomt (Freyhof 2011). 


\subsubsection{Wetenschappelijke kritiek en recentere inzichten}

Hansen et al. (2008) en Jacobsen et al. (2012) stellen dat op basis van enkel een verschil in kieuwboogaanhangsels niet te concluderen is dat de verdwenen Rijn-delta houting een andere soort is in vergelijking met de Deense houting zoals Freyhof en Schöter (2005) claimen. Eén van de redenen hiervoor is dat het aantal kieuwboogaanhangsels weliswaar een sterke erfelijke component heeft, maar ook zeer sterk kan variëren tussen nauwverwante groepen binnen het $C$. lavaretus-complex en geen relatie toont met de genetische lijn waar populaties van afstammen. Bovendien is de morfologische plasticiteit binnen een Coregonus soort erg groot. In een geïsoleerde populatie kunnen er binnen een beperkt aantal generaties al veranderingen in aantallen kieuwboogaanhangels ontstaan onder druk van omgevingsomstandigheden (Østbye et al. 2005, Hansen et al. 2008, Etheridge et al. 2012).

De hypothese van Freyhof \& Schöter (2005) dat de houtingen in de Deense Waddenzee behoren tot de soort C. maraena die rondom de Oostzee voorkomt, is met recenter genetisch en morfologisch onderzoek verworpen, aangezien daarbij significante verschillen tussen de houting uit de Deense Waddenzee en andere houtingachtigen in Denemarken en Oostzee zijn gevonden (Jacobsen et al. 2012). De hypothese dat de Rijndelta-houting een andere soort is dan de Deense houting is hiermee niet ontkracht. Voor het testen van deze hypothese is genetisch onderzoek naar de verdwenen Rijndelta houting populatie noodzakelijk. Deze is momenteel nog niet beschikbaar.

De meest recente studies naar het Coregonus lavaretus-soorten-complex in Noordwest Europa, die de houtingen (met de langste puntige snuiten) en grote marenen (met kortere tot stompe snuiten) omvatten, beschouwen de houting Coregonus oxyrhynchus op basis van genetisch en morfologisch onderzoek als een aparte soort op basis van morfologie én de aanpassing om te kunnen leven in 33\%o zeewater. Dat is uniek binnen het C. lavaretus soortencomplex (Hansen et al. 2008, Jepsen et al. 2012, Jensen et al. 2015). De genetische scheiding is echter van zeer recente oorsprong (na de laatste ijstijd) en de auteurs erkennen dat daarmee de soortstatus controversieel is. Sommige auteurs spreken dan ook liever van de 'North Sea Houting' als 'evolutionairy significant unit (ESU)' die apart moeten worden beheerd en beschermd (Dierlking et al. 2014).

De populatie van houting in de Deense Waddenzee in de Vidaa rivier onderscheidt zich, op basis van snuitlengte en de ecologische eigenschap dat volledig zoutwater van 33\%o ook als habitat kan worden benut, van andere houtingachtigen in Denemarken en de Oostzee. Die kunnen zoutgehalten tot maximaal ongeveer 15\%o tolereren (Hansen et al. 2008), terwijl de Deense Vidaa houtingpopulatie deze kenmerken (lange puntige snuit en tolerantie voor 33\% zeewater), wel gemeen heeft met de uitgestorven 'Rijn-delta' populatie. Het verschil in kieuwboogaanhangels kan duiden op genetische scheiding tussen beide populaties houtingen in de Rijn-delta en Deense Waddenzee, waarbij dergelijke verschillen in aantal kieuwboogaanhangsels zich snel kunnen ontwikkelen onder druk van lokale aanpassing aan omstandigheden (Ozerov et al. 2015).

Op dit moment is de mate van uitwisseling en verwantschap tussen de oorspronkelijke 'Noordzee houting' populatie van de Rijn, Maas en Schelde en de huidige 'Noordzee houting' populatie in de Deense Waddenzee onbekend. Daarmee is de aparte soortstatus voor de Rijn-Maas-Schelde houting zoals geclaimd door Freyhof \& Schöter (2005) vooralsnog niet meer dan een interessante hypothese die niet uitgesloten kan worden (Jacobsen et al. 2012) en alleen met genetisch onderzoek getest kan worden. 


\section{Conclusies en aanbevelingen}

De claim van Freyhof \& Schöter (2005) dat de uitgestorven populatie in de Rijn-delta een aparte soort is en dat C. oryrinchus dus een wereldwijd uitgestorven soort betrof, is daarna, afgezien door de IUCN, niet overgenomen door de wetenschappelijke wereld. Integendeel, er is veel kritiek op de veel te smalle onderbouwing hiervoor. Het hogere gemiddelde aantal kieuwboogaanhangels van de Rijndelta populatie van houting in vergelijking met de houting in de Deense Waddenzee laat wel zien dat deze populatie zich gescheiden van elkaar aan het ontwikkelen waren, maar dat kan zowel heel recent tot een paar duizend jaar geleden gescheiden zijn geraakt of al veel eerder voor de laatste ijstijd (vele tienduizenden jaren terug). Bij een zeer recente scheiding tussen beide houting populaties zullen de genetische verschillen nog zeer klein zijn en zal aparte soortstatus niet aan de orde zijn. Bij een scheiding van tienduizenden jaren kunnen daarentegen flinke genetische verschillen zijn ontstaan en is er wellicht, afhankelijk van de grootte van deze verschillen, wel van een aparte soortstatus sprake. Hierover is, zonder analyse van genetische data van de verdwenen populatie in de Rijn-delta en deze te vergelijken met de al beschikbare genetische data van andere houting populaties, nu geen uitspraak over te doen.

Wat wel is aangetoond is dat de houting uit de Deense Waddenzee zowel genetisch, als ook morfologisch (o.a. in hoge mate van zouttolerantie, een zeer zeldzaam voorkomende eigenschap onder de houtingachtigen), verschilt van de Baltische houting (C. maraena) rondom de Oostzee. De conclusie van Freyhof \& Schöter (2005) dat de Deense Vidaa houting, die stampopulatie is voor herintroductieprogramma's in de Duityse waddenzee en de Rijn, tot C. maraena behoort. Deze inmiddels weerlegde conclusie van Freyhof \& Schöter is echter onterecht wel overgenomen door de IUCN (Freyhof 2011).

Het ligt voor de hand om, bij gebrek aan bewijs voor een aparte soortstatus voor de verdwenen Rijndelta houting, om de houtingen in de Deense Waddenzee nog steeds als dezelfde soort C. oxyrinchus te beschouwen of op z'n minst de houting in het Waddenzee gebied te beschouwen als een zelfstandige 'evolutionairy significant unit (ESU)'. De unieke eigenschappen van die ESU zijn een lange puntige snuit en tolerantie voor 33\%o zeewater. Dit zou dan betekenen dat de geïntroduceerde houting vanuit de Deense Waddenzee ook valt onder de Habitatrichtlijn.

De enige manier om duidelijkheid te krijgen over de status van de houtingpopulatie die in de jaren '30 van de $20^{\mathrm{e}}$ eeuw verdwenen is uit de Rijn-delta is aan de hand van genetisch onderzoek van historisch materiaal. Er zijn in collecties nog wel schubben en ander niet in formaline geconserveerd materiaal van houtingen beschikbaar die onderzocht zouden kunnen worden en er zijn methoden ontwikkeld om hier goede genetische profielen uit op te stellen (Hansen et al. 2008, Nielsen et al. 1999). Met een dergelijk genetisch onderzoek zou kunnen worden bepaald of de Rijn-delta houting een aparte soortstatus verdiende. 


\section{$6 \quad$ Kwaliteitsborging}

Wageningen Marine Research beschikt over een ISO 9001:2008 gecertificeerd kwaliteitsmanagementsysteem (certificaatnummer: 187378-2015-AQ-NLD-RvA). Dit certificaat is geldig tot 15 september 2018. De organisatie is gecertificeerd sinds 27 februari 2001. De certificering is uitgevoerd door DNV Certification B.V. 


\section{Literatuur}

Borcherding J., Scharbert A. \& Urbatzka R., 2006. Timing of downstream migration and food uptake of juvenile North Sea Houting stocked in the Lower Rhine and the Lippe (Germany). Journal of Fish Biology, 68:1271-1286.

Borcherding J., Pickhardt C., Winter H.V. \& Becker J.S., 2008. Migration history of North Sea Houting (Corogonus oxyrinchus L.) caught in Lake IJsselmeer (The Netherlands) inferred from scale transects of ${ }^{88} \mathrm{Sr}:{ }^{44} \mathrm{Ca}$ ratios. Aquatic Sciences, 70 (1): 47656

Borcherding J., Heynen M., Jäger-Kleinicke T., Winter H.V., Eckman R., 2010. Re-establishment of the North Sea houting in the River Rhine. Fisheries Management and Ecology 17: 291-293.

Borcherding J., Breukelaar A.W., Winter H.V., König U., 2014. Spawning migration and larval drift of anadromous North Sea houting (Coregonus oxyrinchus) in the River IJssel, the Netherlands. Ecology of Freshwater Fish 23: 161-170

Bosveld J., 2008. The status and degree of rehabilitation of populations of Houting (Coregonus oxyrinchus) and Twaite shad (Alosa fallax) in the Netherlands. Afstudeerscriptie Universiteit Nijmegen.

De Groot S.J., 1988. Literatuurstudie naar rekolonisatie mogelijkheden van het stroomgebied van de Rijn door riviertrekvissen en echte riviervissen - Deelrapport Houtingachtigen. Rapport M088-208 Nr. 112, Rijksinstituut voor Visserijonderzoek, IJmuiden, 23 pages.

De Groot S.J., 1990a. Decline of the catches of coregonids and migratory smelt in the lower Rhine, the Netherlands - Journal of Applied Ichthyology, 6: 2476251.

De Groot S.J., 1990b. Herstel van riviertrekvissen in de Rijn een realiteit? 3. De Grote \& Kleine marene (Coregonus lavaretus \& C. Albula). De Levende Natuur 91 (6): 2156219.

De Groot S. J., 2002. A review of the past and present status of anadromous fish species in the Netherlands: is restocking the Rhine feasible? Hydrobiologia, 478: 205-218.

De Groot S. J., Nijssen H., 1997. The North Sea Houting, Coregonus oxyrinchus, back in the Netherlands (Pisces, Salmoniformes, Salmonidae). Bulletin Zoölogisch Museum. Universteit van Amsterdam, 16 (4): 21-24.

Dierking J., Phelps L., Præbel K., Ramm G., Prigge E., Borcherding J., Brunke M., Eizaguirre Ch., 2014. Anthropogenic hybridization between endangered migratory and commercially harvested stationary whitefish taxa (Coregonus spp.). Evol. Appl. 7, 1068-1083.

Etheridge E.C., Adams C.E., Bean C.W., Durie N.C., Gowans A.R.D., Harrod C., Lyle A.A., Maitland P.S., Winfield I.J., 2012. Are phenotypic traits useful for differentiating among a priori Coregnous taxa? Journal of Fish Biology 80: 387-407.

Freyhof J., Schöter C., 2005. The Houting Coregonus oxyrinchus (L.) (Salmiformes: Coregonidae), a globally extinct species from the North Sea basin. Journal of Fish Biology, 67: 713-729.

Freyhof J. \& Kottelat M., 2008. Coregonus oxyrinchus. The IUCN Red List of Threatened Species 2008: e.T5380A11126034.

Freyhof J., 2011. Coregonus maraena. The IUCN Red List of Threatened Species 2011: e.T135672A4176316.

Hansen M.M., Mensberg K.L.D., Berg S., 1999. Postglacial recolonization patterns and genetic relationships among Whitefish (Coregonus sp.) populations in Denmark, inferred from mitochondrial DNA and microsatellite markers. Molecular Ecology, 8 (2): 239-252.

Hansen M.M., Nielsen E.E., Mensberg K.L.D., 2006. Underwater but not out of sight: genetic monitoring of effective population size in the endangered North Sea Houting (Coregonus oxyrhynchus). Canadian Journal of Fisheries and Aquatic Sciences, 63 (4): 780-787.

Hansen M.M., Fraser D.J., Als T.D., Mensberg K.L.D., 2008. Reproductive isolation, evolutionary distinctiveness and setting conservation priorities: The case of a European lake whitefish and the endangered North Sea houting (Coregonus spp.). BMC Evolutionary Biology 8: 137

Ingendahl D., Beeck P., 2011. Critical review on the re-introduction of flagship species. Sciences Eaux et Territories no 3.

Jacobsen M.W., Hansen M.M., Orlando L., Bekkevold D., Bernatchez L., Willerslev E., Gilbert M.T.P., 2012. Mitogenome sequencing reveals shallow evolutionary histories and recent divergence time 
between morphologically and ecologically distinct European whitefish (Coregonus spp.). Molecular Ecology 21:2727-2742.

Jensen A.R., Nielsen H.T., Ejbye-Ernst M., 2003. National management plan for the houting. Ministry of the Environment, Forest and Nature Agency, County of Southern Jutland and County of Ribe, Ribe.

Jepsen N., Deacon M., Koed A., 2012 Decline of the North Sea houting: protective measures for an endangered anadromous fish. Endangered Species Research 16: 77-84.

Kranenbarg J., Winter H.V. \& Backx J.J.G.M., 2002. Recent increase of North Sea Houting and prospects for recolonization in the Netherlands. Journal of Fish Biology 61 (Supplement A): 251-253.

Kottelat, M., Freyhof J., 2007. Handbook of European freshwater fishes. Publications Kottelat, Cornol and Freyhof, Berlin. 646 pp.

Nielsen E.E., Hansen M.M., Loeschcke V., 1999. Analysis of DNA from old scale samples: technical aspects, applications and perspectives for conservation. Hereditas 130:265-276.

Østbye K., Bernatchez L., Naesje T.F., Himberg K.J., and Hindar K., 2005. Evolutionary history of the European whitefish Coregonus lavaretus (L.) species complex as inferred from mtDNA phylogeography and gill-raker numbers. Molecular Ecology 14:4371-4387.

Ozerov M.Y., Himberg M., Aykanat T., Sendek D.S., Hager-Strand H., Verliin A., Krause T., Olsson J., Primmer C.R., Vasemagi A. 2015. Generation of a neutral F ST baseline for testing local adaptation on gill raker number within and between European whitefish ecotypes in the Baltic Sea basin. Journal of Evolutionary Biology 28: 1170-1183.

Præbel K., Knudsen R., Siwertsson A., Karhunen M., Kahilainen K.K., Ovaskainen O., Østbye K., Peruzzi F., Fevolden S.E., Amundsen P.A., 2013. Ecological speciation in postglacial European whitefish: rapid adaptive radiations into the littoral, pelagic, and profundal lake habitats. Ecology and Evolution 3:4970-4986.

Redeke H.C., 1934. Über den Rheinschnäpel, Coregonus oxyrhynchus L. Verhandlungen der Internationalen Vereiniging für theoretische und angewandte Limnologie 6: 352-357.

Redeke H.C., 1941. Fauna van Nederland X Pisces (Cyclostomi-Euichthyes) (T1-T11). A.W. Sijthoff's uitgeversmaatschappij N.V., Leiden, The Netherlands, 331 pages.

Schlegel H., 1862. Natuurlijke historie van Nederland. De Visschen xii, G.L. Funke, Amsterdam, The Netherlands, 211 pages.

Van Bemmelen A.A., 1866. Lijst van visschen in Nederland waargenomen. In: Herklots, J.A. (Ed.), Bouwstoffen voor eene Fauna van Nederland, 3, E.J. Brill, Leyden, pp. 318-413.

Van den Ende W.P., 1847. Verslag der werkzaamheden Vereeniging tot Bevordering der Inlandsche Ichtyologie: eerste deel. An. Nijhoff, Arnhem, the Netherlands.

Winter H.V., de Leeuw J.J., Bosveld J., 2008. Houting in het IJsselmeergebied. Een uitgestorven vis terug? IMARES rapport nr. C084/08. 


\section{Verantwoording}

Rapport C115/17

Projectnummer: 4311218007

Dit rapport is met grote zorgvuldigheid tot stand gekomen. De wetenschappelijke kwaliteit is intern getoetst door een collega-onderzoeker en het verantwoordelijk lid van het managementteam van Wageningen Marine Research

Akkoord:

Ir. O.A. van Keeken

onderzoeker

Handtekening:

Datum:

december 2017

Akkoord:

Drs. J. Asjes

Manager integratie

Handtekening:

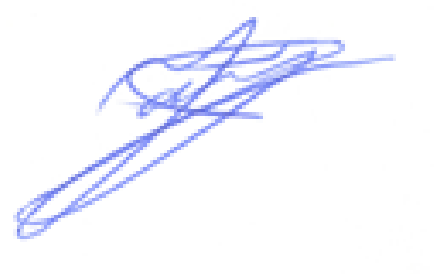

Datum:

december 2017 
Wageningen Marine Research

T: $+31(0) 317480900$

E: marine-research@wur.nl

www.wur.nl/marine-research

Visitors address

- Ankerpark 271781 AG Den Helder

- Korringaweg 7, 4401 NT Yerseke

- Haringkade 1, 1976 CP IJmuiden
Wageningen Marine Research is the Netherlands research institute established to provide the scientific support that is essential for developing policies and innovation in respect of the marine environment, fishery activities, aquaculture and the maritime sector.

Wageningen University \& Research is specialised in the domain of healthy food and living environment.

\section{The Wageningen Marine Research vision:}

'To explore the potential of marine nature to improve the quality of life.'

\section{The Wageningen Marine Research mission}

- To conduct research with the aim of acquiring knowledge and offering advice on the sustainable management and use of marine and coastal areas.

- Wageningen Marine Research is an independent, leading scientific research institute.

Wageningen Marine Research is part of the international knowledge organisation Wageningen UR (University \& Research centre). Within Wageningen UR, nine specialised research institutes of Stichting Wageningen Research (a Foundation) have joined forces with Wageningen University to help answer the most important questions in the domain of healthy food and living environment. 